\title{
Effects of dark chocolate and cocoa consumption on endothelial function and arterial stiffness in overweight adults
}

\author{
Sheila G. West ${ }^{1,2 *}$, Molly D. McIntyre ${ }^{1}$, Matthew J. Piotrowski ${ }^{1}$, Nathalie Poupin ${ }^{3}$, Debra L. Miller ${ }^{4}$, \\ Amy G. Preston ${ }^{4}$, Paul Wagner ${ }^{1}$, Lisa F. Groves ${ }^{1}$ and Ann C. Skulas-Ray ${ }^{2}$ \\ ${ }^{1}$ Department of Biobehavioral Health, The Pennsylvania State University, 219 Biobehavioral Health Building, \\ University Park, PA 16802, USA \\ ${ }^{2}$ Department of Nutritional Sciences, The Pennsylvania State University, 110 Chandlee Laboratory, University Park, \\ PA 16802, USA \\ ${ }^{3}$ AgroParisTech, CRNH-IdF, UMR914 Nutrition Physiology and Ingestive Behavior, F-75005 Paris, France \\ ${ }^{4}$ The Hershey Center for Health and Nutrition, The Hershey Company, 1025 Reese Avenue, Hershey, PA 17033, USA \\ (Submitted 14 December 2012 - Final revision received 25 June 2013 - Accepted 25 June 2013 - First published online 25 November 2013)
}

\begin{abstract}
The consumption of cocoa and dark chocolate is associated with a lower risk of CVD, and improvements in endothelial function may mediate this relationship. Less is known about the effects of cocoa/chocolate on the augmentation index (AI), a measure of vascular stiffness and vascular tone in the peripheral arterioles. We enrolled thirty middle-aged, overweight adults in a randomised, placebo-controlled, 4-week, cross-over study. During the active treatment (cocoa) period, the participants consumed $37 \mathrm{~g} / \mathrm{d}$ of dark chocolate and a sugarfree cocoa beverage (total cocoa $=22 \mathrm{~g} / \mathrm{d}$, total flavanols $(\mathrm{TF})=814 \mathrm{mg} / \mathrm{d}$ ). Colour-matched controls included a low-flavanol chocolate bar and a cocoa-free beverage with no added sugar $(\mathrm{TF}=3 \mathrm{mg} / \mathrm{d})$. Treatments were matched for total fat, saturated fat, carbohydrates and protein. The cocoa treatment significantly increased the basal diameter and peak diameter of the brachial artery by $6 \%(+2 \mathrm{~mm})$ and basal blood flow volume by $22 \%$. Substantial decreases in the AI, a measure of arterial stiffness, were observed in only women. Flow-mediated dilation and the reactive hyperaemia index remained unchanged. The consumption of cocoa had no effect on fasting blood measures, while the control treatment increased fasting insulin concentration and insulin resistance $(P=0 \cdot 01)$. Fasting blood pressure (BP) remained unchanged, although the acute consumption of cocoa increased resting BP by $4 \mathrm{mmHg}$. In summary, the high-flavanol cocoa and dark chocolate treatment was associated with enhanced vasodilation in both conduit and resistance arteries and was accompanied by significant reductions in arterial stiffness in women.
\end{abstract}

Key words: Cocoa: Chocolate: Endothelium: Flow-mediated dilation

Dysfunction of the vascular endothelium is considered to be an important early step in the development of atherosclerosis ${ }^{(1)}$, and improvements in endothelial function have been observed in studies of high-flavanol foods and beverages, including tea ${ }^{(2,3)}$, red wine ${ }^{(4,5)}$, cocoa and chocolate ${ }^{(6-13)}$. A recent meta-analysis $^{(14)}$ of eight randomised trials has concluded that the vascular effects of high-flavanol cocoa/chocolate were dose dependent and of sufficient magnitude to reduce cardiovascular risk. However, many of these studies ${ }^{(7,15-17)}$ involved acute exposure, lasting from a few hours to a few days. Sustained improvements in flow-mediated dilation (FMD) of the brachial artery with treatment periods lasting from 1 to 3 months have been reported by three previous studies ${ }^{(11,13,18)}$. However, sustained effects were not evident in a study of adults with CHD after 6 weeks of treatment ${ }^{(9)}$. Given that some vasodilatory drugs (e.g. nitroglycerin) exhibit tolerance with repeated dosing ${ }^{(19)}$, it is important to understand whether or not cocoa/chocolate may have the same effects on conduit artery vasodilation, even after sustained exposure.

Most vascular studies of cocoa/chocolate have focused on changes in endothelium-dependent vasodilation. There is preliminary evidence that cocoa products also reduce the augmentation index (AI), a measure of arterial stiffness ${ }^{(15,20)}$ The AI is measured using pulse amplitude tonometry and pulse wave analysis ${ }^{(21)}$. In individuals with stiff arteries, the pressure wave travels rapidly from the aorta to the peripheral arterioles, where it encounters resistance. This results in a reflected pressure wave that rapidly travels back to the

Abbreviations: AI, augmentation index; BP, blood pressure; fRHI, Framingham reactive hyperaemia index; FMD, flow-mediated dilation; RHI, reactive hyperaemia index.

*Corresponding author: Dr S. G. West, fax +1 8148637525 , email sgw2@psu.edu 
heart, thus augmenting central systolic pressure ${ }^{(21,22)}$. The AI increases with age ${ }^{(23)}$ and is higher in individuals at elevated CVD risk ${ }^{(24)}$. In a cross-sectional study of 198 adults, habitual cocoa consumption $(>4.6 \mathrm{mg} / \mathrm{d})$ has been reported to be associated with a lower AI, when compared with infrequent cocoa consumption ${ }^{(20)}$. However, a more recent study with a larger sample size has not confirmed this relationship, perhaps because retrospective recall is not the most effective way to assess habitual intake ${ }^{(25)}$. Only one prospective, randomised study has examined the AI after the consumption of highflavanol chocolate. Vlachopoulos et al. ${ }^{(15)}$ observed significant reductions in the $\mathrm{AI} 90-180 \mathrm{~min}$ after the consumption of a $100 \mathrm{~g}$ dose of dark chocolate than after a control procedure (sham eating). It is unknown whether acute effects on the AI are sustained with longer treatment or whether they are evident following the consumption of a more moderate dose of cocoa/chocolate. Thus, the purpose of the present study was to conduct a comprehensive assessment of large and small vessel dilatation, peripheral blood flow and arterial stiffness after treatment with cocoa and dark chocolate $v$. a matched control treatment over a 4-week period.

\section{Experimental methods}

\section{Participants}

In the present study, thirty overweight or moderately obese individuals (BMI $25-37 \mathrm{~kg} / \mathrm{m}^{2}$ ), aged $40-64$ years, participated (mean age 52.6 ( $\operatorname{se} 0 \cdot 40$ ) years). To avoid fluctuations in endothelial function across the normal menstrual cycle, only women who were postmenopausal (no menses $>12$ months) and were not taking hormone therapy were enrolled. Exclusion criteria included the use of medications with cardiovascular or metabolic effects, use of medications for sleep or mood disorders, current use of tobacco, intention to lose weight, history or current diagnosis of CVD, blood pressure (BP) $\geq 140 / 100 \mathrm{mmHg}$, diabetes or screening glucose levels $\geq 1260 \mathrm{mg} / \mathrm{l}$ and Raynaud's syndrome. The use of vitamins and other supplements was discontinued 2 weeks before participation and throughout the study period. The participants were required to abstain from eating chocolate and/or cocoa-containing products, except those provided during the study period. The study criteria were met by fifty-seven participants after a phone screening, and thirty-seven were eligible following a clinic screening that included a chemistry panel (including liver and kidney function), complete blood count, lipid profile, 12-lead electrocardiogram, brief physical examination and review of medical history. Of the initial thirty-seven eligible participants who were enrolled into the study, seven were excluded due to weight loss $>10 \%$ of body weight ( $n$ 1), dislike of test products ( $n 2)$, change in work schedule ( $n 1)$, change in medication $(n 1)$, presence of an undisclosed medical device that would interfere with data collection $(n 1)$, and not providing any reason for study withdrawal $(n 1)$. The present study was conducted according to the guidelines laid down in the Declaration of Helsinki, and all procedures involving human subjects were approved by the Institutional Review Board of The Pennsylvania State University. Written informed consent was obtained from all the subjects.

\section{Study design and intervention}

The present study was a randomised, double-blind, twoperiod, cross-over design. The 4-week treatment periods (cocoa/chocolate $v$. control) were separated by a minimum of 2 weeks. On each day of the cocoa/chocolate treatment, the participants consumed $37 \mathrm{~g} / \mathrm{d}$ dark chocolate (Hershey's ${ }^{\circledR}$ EXTRA DARK Chocolate) and a sugar-free cocoa beverage (total dose of natural cocoa $=22 \mathrm{~g} / \mathrm{d}$, total flavanols $=814$ $\mathrm{mg} / \mathrm{d}$ ). The control treatment included a low-flavanol chocolate bar and a cocoa-free beverage mix with no added sugar (total flavanols $=3 \mathrm{mg} / \mathrm{d}$ ). The participants were instructed to consume the test products in place of a daily snack. The beverages and bars were similar in appearance and were matched for total fat, saturated fat, protein and carbohydrates (Table 1).

The total antioxidant activity of the active and control products was measured using the oxygen radical absorbance capacity assay ${ }^{(26,27)}$ (Table 2 ). The concentrations of total polyphenols were measured using the colorimetric method of Singleton \& Rossi ${ }^{(28)}$. The concentrations of total flavanols were determined using three different methods

Table 1. Nutrient profiles of test materials

\begin{tabular}{|c|c|c|c|c|c|c|}
\hline & Chocolate bar & Cocoa beverage & Active total & Control bar & Control beverage & Control total \\
\hline \multicolumn{7}{|l|}{ Energy } \\
\hline kcal & 172 & 24 & 196 & 181 & 47 & 228 \\
\hline kJ & 720 & 100 & 821 & 758 & 197 & 955 \\
\hline Total fat $(\mathrm{g})$ & 13 & 1 & 14 & 12 & 2 & 14 \\
\hline Saturated fat (g) & 8 & 1 & 9 & 6 & 2 & 8 \\
\hline Carbohydrates (g) & 20 & 6 & 26 & 21 & 6 & 27 \\
\hline Dietary fibre (g) & 4 & 5 & 9 & 0 & 0 & 0 \\
\hline Sugar (g) & 14 & 0 & 14 & 21 & 5 & 26 \\
\hline Protein (g) & 3 & 3 & 6 & 3 & 2 & 5 \\
\hline Cholesterol (mg) & 3 & 0 & 3 & 5 & 1 & 6 \\
\hline $\mathrm{Ca}(\mathrm{mg})$ & 21 & 14 & 35 & 116 & 93 & 209 \\
\hline $\mathrm{Mg}(\mathrm{mg})$ & 74 & 67 & 141 & 10 & 11 & 21 \\
\hline $\mathrm{K}(\mathrm{mg})$ & 195 & 218 & 413 & 84 & 120 & 204 \\
\hline $\mathrm{Na}(\mathrm{mg})$ & 6 & 65 & 71 & 59 & 120 & 179 \\
\hline Caffeine (mg) & 23 & 16 & 39 & 2 & 0 & 2 \\
\hline Theobromine (mg) & 264 & 212 & 476 & 3 & 1 & 4 \\
\hline
\end{tabular}


Table 2. Flavanol compounds and antioxidant activity

\begin{tabular}{|c|c|c|c|c|c|c|c|}
\hline Chemistry & Subclass (units) & $\begin{array}{c}\text { Chocolate } \\
\text { bar }\end{array}$ & $\begin{array}{c}\text { Cocoa } \\
\text { beverage }\end{array}$ & $\begin{array}{c}\text { Active } \\
\text { total }\end{array}$ & $\begin{array}{c}\text { Control } \\
\text { bar }\end{array}$ & $\begin{array}{c}\text { Control } \\
\text { beverage }\end{array}$ & $\begin{array}{c}\text { Control } \\
\text { total }\end{array}$ \\
\hline Antioxidant activity & ORAC ( $\mu \mathrm{mol}$ TE/serving) & $13320 \cdot 0$ & $12344 \cdot 0$ & 25664.0 & $685 \cdot 0$ & $4320 \cdot 0$ & $5005 \cdot 0$ \\
\hline Polyphenols & Total polyphenols (mg GAE/serving) & $555 \cdot 0$ & $281 \cdot 0$ & $836 \cdot 0$ & $14 \cdot 0$ & $152 \cdot 0$ & $166 \cdot 0$ \\
\hline \multirow[t]{15}{*}{ Flavanols } & Monomers (mg/serving) & & & & & & \\
\hline & Epicatechin & $32 \cdot 6$ & 41.0 & $73 \cdot 6$ & 0.9 & 0.0 & 0.9 \\
\hline & Catechin & 5.9 & $18 \cdot 7$ & $24 \cdot 6$ & 0.2 & 0.0 & 0.2 \\
\hline & Polymers (mg/serving) & & & & & & \\
\hline & Dimer (DP2) & $22 \cdot 6$ & $26 \cdot 3$ & 48.9 & 0.0 & 0.0 & 0.0 \\
\hline & Trimer (DP3) & 20.7 & $22 \cdot 8$ & 43.5 & 0.0 & 0.0 & 0.0 \\
\hline & Tetramer (DP4) & 20.7 & $19 \cdot 3$ & $40 \cdot 0$ & 0.0 & 0.0 & 0.0 \\
\hline & Pentamer (DP5) & $17 \cdot 9$ & $14 \cdot 6$ & $32 \cdot 5$ & 0.0 & 0.0 & 0.0 \\
\hline & Hexamer (DP6) & $15 \cdot 5$ & $12 \cdot 1$ & $27 \cdot 6$ & 0.0 & 0.0 & 0.0 \\
\hline & Heptamer (DP7) & $13 \cdot 1$ & $9 \cdot 3$ & $22 \cdot 4$ & 0.0 & 0.0 & 0.0 \\
\hline & Octamer (DP8) & $11 \cdot 7$ & $7 \cdot 7$ & $19 \cdot 4$ & 0.0 & 0.0 & 0.0 \\
\hline & Nonomer (DP9) & $8 \cdot 3$ & $5 \cdot 6$ & $13 \cdot 9$ & 0.0 & 0.0 & 0.0 \\
\hline & Decamer (DP10) & 8.7 & $6 \cdot 1$ & $14 \cdot 8$ & 0.0 & 0.0 & 0.0 \\
\hline & Total polymers & $139 \cdot 2$ & $123 \cdot 8$ & 263.0 & 0.0 & 0.0 & 0.0 \\
\hline & Total flavanols (mg/serving) & $347 \cdot 0$ & $440 \cdot 0$ & 814.0 & 1.0 & $2 \cdot 0$ & 3.0 \\
\hline
\end{tabular}

ORAC, oxygen radical absorbance capacity; TE, Trolox equivalents; GAE, gallic acid equivalents; DP, degree of polymerisation.

(each analytical method was optimised to assess a specific subgroup of flavanols). The concentrations of flavanol monomers, epicatechin and catechin, were measured using liquid chromatography/APCI-MS ${ }^{(29)}$, and those of the flavanol dimer through decamer polymers (DP2-10) were measured using liquid chromatography/MS ${ }^{(30,31)}$. The concentrations of total flavanols were measured using the colorimetric DMAC (4-dimethylaminocinnamaldehyde) method. The DMAC assay is unique in that it measures the concentrations of all flavanols including those of monomers (epicatechin and catechin), gallated flavanols, and flavanol polymers (DP2 to DP10) and polymers greater than DP10 ${ }^{(22)}$

Before each blood draw and vascular test, the participants were asked to avoid the consumption of alcohol and high-flavanoid foods for $48 \mathrm{~h}$; food lists were provided to guide appropriate food choices. Vigorous exercise was prohibited on test days. Waist and hip circumferences were measured in triplicate by nurses, according to a standardised protocol $^{(32)}$. All tests were conducted between 07.00 and 11.00 hours.

Before randomisation, blood sample collection and vascular assessments were carried out after a $12 \mathrm{~h}$ fast. At the end of each treatment period, vascular assessments were carried out $2 \mathrm{~h}$ after the consumption of the last dose of test products (including one bar and one beverage). In keeping with several previous vascular studies, the $2 \mathrm{~h}$ time point was selected to coincide with the peak plasma concentrations of flavanols ${ }^{(33)}$ and peak vascular response in studies of acute exposure $^{(7,11,16)}$. Fasting blood samples were collected at the end of each 4-week treatment period from thirteen of the thirty participants.

\section{Ultrasound measures of the diameter and flow-mediated dilation of the brachial artery}

FMD and arterial diameter were measured using highfrequency ultrasound as described previously ${ }^{(34-36)}$ in a quiet, dimly lit room at $22-24^{\circ} \mathrm{C}$. Our laboratory has previously reported robust test-retest reliability for this measurement ${ }^{(35)}$ The brachial artery above the elbow of the right arm was scanned in a longitudinal section after 15 min of rest, and continuous cross-sectional images were recorded at rest $(1 \mathrm{~min})$, during cuff inflation $(5 \mathrm{~min})$, and during increased blood flow after cuff release ( $2 \mathrm{~min}$ ). An automated rapid cuff inflator set to $250 \mathrm{mmHg}$ (Hokanson) was placed on the forearm, distal to the ultrasound probe. Changes in arterial diameter were measured using external B-mode ultrasound imaging (Acuson Aspen 128XP equipped with a $10 \mathrm{mHz}$ linear array transducer; Acuson) by a single well-trained sonographer (P. W.). Images were gated using R-wave detection so that scans could be assessed at end diastole.

Quantification of arterial diameter and flow-mediated dilation. Automated edge detection software (Brachial Analyzer; MIA) was used to quantify arterial diameter continuously, throughout the test period. The peak arterial diameter was determined as the largest diameter recorded in the 2 min post-deflation segment. Resting diameters are reported as the average diameter in all the images collected over a 1 min period. FMD was calculated by two independent scorers as percent change in arterial diameter at peak dilation $v$. baseline and is reported as a percent. FMD is reported as the average of the two scores.

Measurement of reactive hyperaemia (change in flow volume following cuff release). Using duplex pulsed Doppler, we measured the average flow velocity $(\mathrm{m} / \mathrm{s})$, maximum flow velocity, and velocity time integral during the resting baseline period and immediately after cuff release. Flow $(\mathrm{ml} / \mathrm{min})$ was calculated as described previously ${ }^{(35)}$.

\section{Peripheral arterial tonometry}

During the FMD test, the EndoPAT2000 (Itamar Medical Limited) was used to measure relative changes in peripheral pulse wave amplitude before $v$. after occlusion ${ }^{(37)}$. The EndoPAT technique has been validated as a procedure to measure endothelium-dependent vasodilation ${ }^{(37)}$. We have 
demonstrated a low variability for this measure over repeated visits $^{(38)}$. On the index fingers of the right (ischaemic) and left (control) hands of the participants, two flexible probes were placed. Measurements were taken at baseline $(5 \mathrm{~min})$, during occlusion ( $5 \mathrm{~min}$ ) and during reactive hyperaemia ( $5 \mathrm{~min}$ ). The reactive hyperaemia index (RHI) was calculated as the ratio of the average pulse wave amplitude during hyperaemia (60 to $120 \mathrm{~s}$ of the post-occlusion period) to the average pulse wave amplitude during baseline in the occluded hand over the same values in the control hand multiplied by a baseline correction factor. Low RHI scores have been reported to be prospectively associated with increases in CVD risk over a 6-year follow-up period ${ }^{(39)}$. The Framingham reactive hyperaemia index (fRHI) is an alternative calculation derived from the same raw data. The fRHI uses the period from 90 to $120 \mathrm{~s}$ after cuff release, does not incorporate a baseline correction factor, and has a natural log transformation applied to the resulting ratio ${ }^{(40)}$. The $\mathrm{fRHI}$ is inversely correlated with other CVD risk markers, such as BMI and the total:HDL-cholesterol (HDL-C) ratio ${ }^{(40,41)}$. The EndoPAT device calculates the AI from the shape of the pulse wave under resting conditions. The AI can be adjusted to a heart rate of 75 beats/min to correct for the independent effect of heart rate on this measure ${ }^{(42)}$. Both unadjusted and adjusted AI are reported here.

\section{Blood pressure}

On a separate day, fasting BP was measured using an automated, oscillometric device (Dinamap Pro 100; GE Medical Systems) after a $20 \mathrm{~min}$ rest period. The participants were seated, with their arms at the heart level, and appropriately sized cuffs were used. The time of day was held constant, and the average of three readings was recorded. This procedure was repeated $2 \mathrm{~h}$ after the consumption of the final dose of cocoa products. BP is reported as the mean of three readings collected during the 20 min rest period.

\section{Metabolic parameters}

Lipids and lipoproteins. Whole blood was drawn into serum separator tubes, allowed to clot and centrifuged. The concentrations of total cholesterol and TAG were determined using enzymatic procedures (Quest Diagnostics; CV $<2 \%$ for both) ${ }^{(43)}$. The concentration of HDL-C was estimated according to the modified heparin-manganese procedure (CV $<2 \%$ ). The concentration of LDL-cholesterol (LDL-C) was calculated using the Friedewald equation:

$$
\mathrm{LDL}-\mathrm{C}=\mathrm{TC}-(\mathrm{HDL}-\mathrm{C}+\mathrm{TAG} / 5)
$$

The inter-assay CV was less than 3\%.

Inflammatory markers. The plasma concentrations of IL-1 $\beta$, IL-6 and TNF- $\alpha$ were measured using high-sensitivity ELISA kits obtained from R\&D Systems in duplicate (assay $\mathrm{CV}<11 \%$ for all). In samples collected $2 \mathrm{~h}$ after the consumption of the last dose of cocoa/chocolate or control, the serum concentration of high-sensitivity C-reactive protein was measured using latex-enhanced immunonephelometry (Quest Diagnostics; assay CV $<8 \%$ ).
Insulin and glucose. The concentration of insulin was measured by RIA using ${ }^{125}$ I-labelled human insulin and a human insulin antiserum (Linco Research; cross-reactivity with proinsulin $<0 \cdot 2 \%)^{(44)}$. The concentration of glucose was determined with an immobilised enzyme biosensor using the YSI 2300 STAT Plus Glucose \& Lactate Analyzer (Yellow Springs Instruments). The homeostatic model of insulin resistance (HOMA-IR) was calculated as follows ${ }^{(45)}$ :

$$
\begin{aligned}
\text { HOMA-IR }= & \text { fasting glucose }(\mathrm{mmol} / \mathrm{l}) \\
& \times \text { fasting insulin }(\mu \mathrm{U} / \mathrm{l}) / 22 \cdot 5 .
\end{aligned}
$$

Renin, angiotensin-converting enzyme and angiotensin. Changes in renin activity, angiotensin-converting enzyme activity and angiotensin II activity were measured based on previous research that showed reductions in angiotensinconverting enzyme activity after the consumption of chocolate $^{(43)}$. RIA were used to measure plasma renin activity and angiotensin II activity (Diagnostic Systems Laboratories, Inc.). Angiotensin-converting enzyme activity was measured using an enzymatic assay at The Milton S. Hershey Medical Center core laboratory.

Statistical analyses. Variables were tested for normality and transformed where appropriate. Non-transformed values are reported as means with their standard errors. Treatment effects were examined using the mixed model procedure in the Statistical Analysis Systems statistical software package version 9.2 (SAS Institute). Initial models for the analysis of vascular parameters, BP and fasting blood variables included treatment (baseline, cocoa + chocolate, or control), period and treatment $\times$ period interaction as fixed effects, with participant as a random effect. There was no indication of carry-over: the treatment $\times$ period interaction was not significant. This interaction was removed from the final models. The treatment $\times$ sex interaction was significant only for the $\mathrm{AI}$ and the AI at 75 beats/min, and these results are presented separately by sex. Because the female participants were older, on average, data are presented after adjustment for age. Significant treatment effects (two-sided $P \leq 0.05$ ) were interrogated with Tukey's post hoc tests, where appropriate. The present study was powered $(\beta=0.90)$ to detect a relative increase in FMD of $25 \%^{(35)}$ and a 0.25 unit change in $\mathrm{RHI}^{(38)}$. Based on our previous work, the sample of thirty participants was sufficient to detect a $10 \%$ change in LDL levels and a $7 \cdot 2$ unit change in the AI.

\section{Results}

The baseline characteristics of the participants are given in Table 3. We observed marked peripheral vasodilation following the cocoa + chocolate treatment (Table 4). The increase in the diameter of the brachial artery was evident before reactive hyperaemia $(P=0.001)$ and at the peak dilation following cuff release $(P=0.0001)$. As a result, FMD (expressed as percent change from basal diameter) did not differ by treatment. In addition, resting $(P=0.04)$ and peak $(P=0.03)$ hyperaemic blood flow significantly increased following the chocolate $v$. control treatment (mean increase $=22$ and $12 \%$ for the basal and peak hyperaemic blood flow, respectively). 
Table 3. Characteristics of the participants before treatment ${ }^{*}$

(Least-squares mean values with their standard errors)

\begin{tabular}{lcc}
\hline & Mean & SE \\
\hline Female (\%) & \multicolumn{2}{c}{49.9} \\
Age (years) & 51.7 & 1.2 \\
Body weight (kg) & 81.4 & 2.3 \\
Height $(\mathrm{m})$ & 1.7 & 0.02 \\
BMI $\left(\mathrm{kg} / \mathrm{m}^{2}\right)$ & 27.8 & 0.6 \\
\hline *Pre-treatment values for other CVD risk factors \\
are presented in Tables $4-6$.
\end{tabular}

There were no treatment differences for RHI and fRHI, the measures of endothelial function derived from the EndoPAT device (Table 4). Fig. 1 shows that the reductions in arterial stiffness were largest for the female participants, resulting in a significant treatment $\times$ sex interaction, for the $\mathrm{AI}(P=0.05)$ and the $\mathrm{AI}$ at 75 beats $/ \mathrm{min}(P=0.02)$. The dark chocolate/cocoa treatment decreased the AI by $83 \%$ and the AI at 75 beats $/ \mathrm{min}$ by $129 \%$ in women, relative to the pre-treatment value $(P=0.01)$. In contrast, in men, the $\mathrm{AI}$ was not significantly different after the chocolate treatment.

There were no significant treatment differences for body weight, BMI, waist circumference, hip circumference or the waist:hip ratio (Table 4). After 4 weeks of treatment, there were no changes in fasting BP or heart rate. There were modest, but statistically significant increases in systolic BP
$(P=0.02)$, diastolic BP $(P=0.005)$ and heart rate $(P=0.02)$ $2 \mathrm{~h}$ after the consumption of the final dose of cocoa + chocolate relative to the control treatment (Table 5). Among the fasting blood variables, only insulin concentration and HOMA-IR showed significant increases after the control $v$. cocoa + chocolate treatment (Table 6).

\section{Discussion}

In the sample of healthy, overweight adults in the present study, 4 weeks of daily consumption of cocoa and dark chocolate (equivalent to $22 \mathrm{~g} / \mathrm{d}$ of natural cocoa) was associated with significant increases in basal and peak arterial diameter and increased arterial blood flow through the brachial artery. In only women, there were significant reductions in peripheral arterial stiffness. Taken together, these changes reflect peripheral vasodilation, both in the smaller resistance arteries and in the major conduit artery serving the forearm. This pattern (increased arterial diameter, together with greater flow volume and reduction in the AI) was also observed by Vlachopoulos et al. ${ }^{(15)}$ a few hours after the consumption of a single dose of high-flavanol cocoa. Reductions in the AI have been observed in habitual cocoa consumers ${ }^{(20)}$, although this finding is not universal ${ }^{(25)}$, and previous studies have not presented data separately by sex. Given that women had a higher $\mathrm{AI}$ at baseline, it is unclear whether the sex difference in response to treatment is dependent on ceiling/floor effects,

Table 4. Effects of treatments on vascular outcomes and anthropometricst

(Adjusted mean values with their standard errors)

\begin{tabular}{|c|c|c|c|c|c|c|}
\hline & \multicolumn{2}{|c|}{ Pre-treatment $\ddagger$} & \multicolumn{2}{|c|}{ Control§ } & \multicolumn{2}{|c|}{ Active§ } \\
\hline & Mean & SE & Mean & SE & Mean & $\overline{S E}$ \\
\hline \multicolumn{7}{|l|}{ Ultrasound measurements } \\
\hline Basal arterial diameter $(\mathrm{mm}) \|$ & $4 \cdot 20^{\star \star \star}$ & 0.17 & $4 \cdot 21^{\star \star \star}$ & 0.17 & 4.47 & 0.17 \\
\hline Peak arterial diameter $(\mathrm{mm}) \|$ & $4 \cdot 39^{\star \star \star}$ & 0.18 & $4.42^{\star \star \star}$ & 0.18 & 4.65 & 0.18 \\
\hline FMD ( $\%$ change) & 4.73 & 0.41 & 5.12 & 0.44 & 4.25 & 0.44 \\
\hline \multicolumn{7}{|l|}{ Doppler-derived measures } \\
\hline Basal flow volume $(\mathrm{ml} / \mathrm{s}) \|$ & $166^{\star \star}$ & 18 & $176^{*}$ & 18 & 214 & 18 \\
\hline Peak flow volume $(\mathrm{ml} / \mathrm{s})$ ? & $1059^{*}$ & 76 & $1032^{*}$ & 77 & 1153 & 77 \\
\hline Reactive hyperaemia ( $\%$ change) $\dagger \dagger$ & $612^{*}$ & 37 & 567 & 39 & 503 & 39 \\
\hline \multicolumn{7}{|l|}{ EndoPAT variables } \\
\hline $\mathrm{RHI}$ & $2 \cdot 26$ & 0.14 & $2 \cdot 19$ & 0.12 & $2 \cdot 20$ & 0.11 \\
\hline fRHI & 0.60 & 0.09 & 0.55 & 0.08 & 0.49 & 0.07 \\
\hline Alfł & $9 \cdot 92^{\star *}$ & 3.9 & $5 \cdot 90^{\star *}$ & 3.6 & -0.57 & 3.5 \\
\hline Al at $75 \mathrm{bpm} \S \S$ & $2 \cdot 75^{\star \star}$ & 3.9 & $-2 \cdot 72^{\star *}$ & 3.6 & -8.53 & 3.5 \\
\hline \multicolumn{7}{|l|}{ Anthropometrics } \\
\hline Weight (kg) & $80 \cdot 9$ & $2 \cdot 3$ & $80 \cdot 7$ & $2 \cdot 3$ & $81 \cdot 3$ & $2 \cdot 3$ \\
\hline $\mathrm{BMI}\left(\mathrm{kg} / \mathrm{m}^{2}\right)$ & $27 \cdot 4$ & 0.5 & $27 \cdot 5$ & 0.5 & $27 \cdot 7$ & 0.5 \\
\hline Waist circumference $(\mathrm{cm})$ & 94.6 & $1 \cdot 2$ & 94.7 & $1 \cdot 2$ & $95 \cdot 5$ & $1 \cdot 2$ \\
\hline Hip circumference $(\mathrm{cm})$ & $106 \cdot 8$ & 0.9 & $106 \cdot 9$ & 0.9 & $106 \cdot 9$ & 0.9 \\
\hline Waist:hip ratio & 0.89 & 0.01 & 0.89 & 0.01 & 0.89 & 0.01 \\
\hline
\end{tabular}

FMD, flow-mediated dilation; $\mathrm{RHI}$, reactive hyperaemia index; $\mathrm{fRHI}$, Framingham reactive hyperaemia index; $\mathrm{Al}$, augmentation index; $\mathrm{Al}$ at $75 \mathrm{bpm}$, the augmentation index normalised for a heart rate of 75 beats $/ \mathrm{min}$.

Mean values were significantly different from those of the active group: ${ }^{*} P \leq 0.05,{ }^{\star *} P \leq 0.01,{ }^{\star \star *} P \leq 0.001$.

$\dagger$ Data were obtained from the mixed model procedure in SAS. Tukey's post hoc comparison test was used for multiple comparisons.

$\ddagger$ Pre-treatment testing was carried out in the fasting state.

$\S$ At the end of each 4-week treatment period, vascular tests were carried our $2 \mathrm{~h}$ after the consumption of the last treatment dose.

\|There was a significant main effect of treatment $(P=0.0001)$.

I There was a significant main effect of treatment $(P=0.02)$.

†† There was a significant main effect of treatment $(P=0.05)$.

括 There was a significant main effect of treatment $(P=0.0008)$

$\S \S$ There was a significant main effect of treatment $(P=0.05)$. 


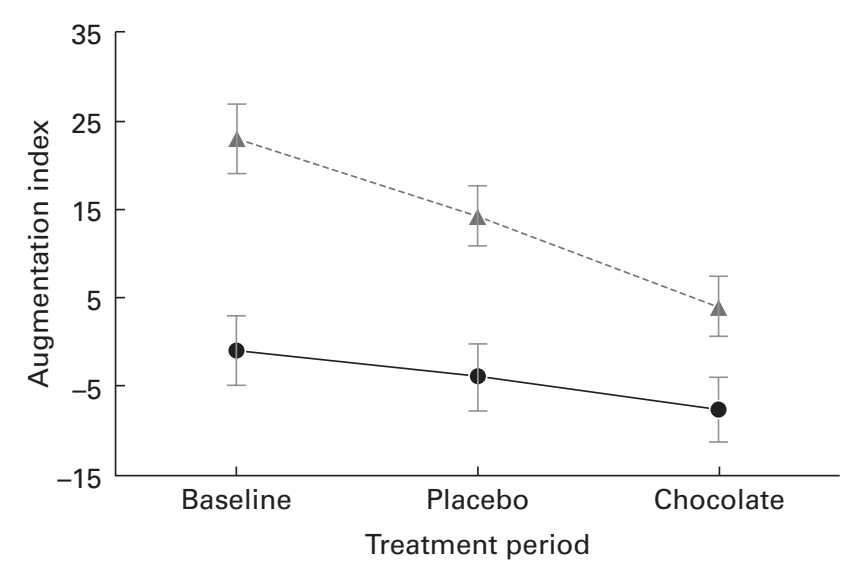

Fig. 1. Sex difference in vascular response to the cocoa + dark chocolate treatment. Women (-.-) exhibited significant reductions in the augmentation index, whereas men (-๑) ) did not (sex $\times$ treatment interaction, $P=0.01$ ).

a true sex difference in physiology, or age. Future studies should enrol age-matched men and women to confirm the source of this effect.

In contrast to several previous studies, more targeted measures of vascular endothelial function (FMD, RHI and fRHI) remained unchanged. However, we observed that significant vasodilation was evident both before and after the hyperaemic stimulus. We cannot rule out sustained improvement in tonic endothelial release of $\mathrm{NO}$ as a mechanism for the basal vasodilation observed in the present study. We encourage investigators to report arterial diameters and flow volume in addition to FMD in future publications

There is convergent evidence from clinical trials ${ }^{(14,46)}$, animal models ${ }^{(47-49)}$ and in vitro studies ${ }^{(16,48)}$ that high-flavanol cocoa and chocolate enhance endothelium-dependent vasodilation, primarily by increasing $\mathrm{NO}$ production. In studies of human endothelial cells, cocoa flavanols have been reported to lower vascular arginase activity ${ }^{(48)}$, suggesting a possible mechanism for increases in NO levels. Several mechanistic studies have identified epicatechin ${ }^{(16)}$ as a critical bioactive compound in cocoa. Recent studies have indicated that cocoa flavanols stimulate $\mathrm{NO}$ production in endothelial cells $^{(7,11)}$. The oral administration of $(-)$-epicatechin, a flavanol found in very high concentrations in cocoa, has been reported to result in acute increases in NO production and vasodilation in healthy men ${ }^{(50)}$. It has also been demonstrated that the vasodilation observed following the consumption of flavanol-rich cocoa is associated with increases in circulating bioactive NO levels and that the inhibition of $\mathrm{NO}$ production prevents cocoa-induced vasodilation ${ }^{(6,16,51)}$.

Previous studies ${ }^{(6,11,52-54)}$ on cocoa/chocolate have reported reductions in $\mathrm{BP}$ in adults with elevated $\mathrm{BP}^{(55,56)}$ or no change in $\mathrm{BP}$ in normotensive individuals (for a review, see Hooper et al. ${ }^{(46)}$ and Ried et al. ${ }^{(54)}$ ). In our normotensive sample, 4 weeks of cocoa + chocolate treatment had no effect on fasting BP. Systolic BP increased by $6 \mathrm{mmHg}(v .2 \mathrm{mmHg}$, after the control treatment, $P=0.03) 2 \mathrm{~h}$ after the consumption of a full day's dose of cocoa + chocolate by the participants. Monahan et $a l^{(12)}$ have recently examined the acute effects of increasing doses of cocoa on endothelial function and BP.
They found that the highest dose $(26 \mathrm{~g})$ increased systolic BP by $6 \mathrm{mmHg}$ ( $v .3 \mathrm{mmHg}$ in the control). As in the present study, small increases in systolic BP were accompanied by substantial decreases in peripheral vasoconstriction. Other studies involving the acute administration of cocoa or chocolate have reported no change $\mathrm{f}^{(7,10,15,43,57)}$ or a decrease in $\mathrm{BP}^{(17)}$. Although dietary fat has been shown to increase $\mathrm{BP}$ acutely $^{(58)}$, our treatments were matched for fat content. It is more likely that the stimulant effects of caffeine or theobromine, inherent to cocoa and chocolate, may be responsible. The present results should be viewed with caution because a recent meta-analysis of thirteen longer-term studies has concluded that chocolate and cocoa have no effect on BP in healthy adults and that lower BP is observed in individuals with elevated $\mathrm{BP}^{(54)}$. We observed that the acute changes in the present study were well within the normotensive range.

Previous studies ${ }^{(56,59)}$ have observed improvements in insulin levels or insulin resistance with the consumption of high-flavanol cocoa/chocolate. In a recent meta-analysis of seven clinical studies, a pooled analysis has revealed significant reductions in HOMA-IR (-0.67; 95\% CI -0.98, 0.36), driven by reductions in serum insulin levels $(-2.65 \mu \mathrm{U} / \mathrm{ml}$; $95 \%$ CI $-4.65,0.65 \mu \mathrm{U} / \mathrm{ml}$ ) following the consumption of cocoa/chocolate. The same interventions had no effect on the levels of fasting glucose, HbA1c or QUICKI (quantitative insulin sensitivity check index $)^{(1)}$. In the present study, the control treatment was associated with increased fasting insulin levels and greater insulin resistance $v$. pre-treatment. Insulin resistance remained unchanged following the cocoa + chocolate treatment, and the two treatments did not differ. As expected, body weight and fasting lipid levels did not differ significantly from those observed during the control treatment or pre-treatment.

The present study has several limitations. The most important one is that we carried out all the vascular assessments $2 \mathrm{~h}$ after the consumption of the final dose, thus confounding the acute and chronic effects of cocoa + chocolate. However, time course studies have shown that the improvement in endothelial function is greatest $2 \mathrm{~h}$ after the consumption of the dose $\mathrm{e}^{(11,16,51)}$, and several previous studies have assessed post-treatment FMD at $2 \mathrm{~h}^{(13,17,57)}$. Nested designs, in which

Table 5. Blood pressure and heart rate after 4 weeks of treatment $\dagger$ (Adjusted mean values with their standard errors)

\begin{tabular}{|c|c|c|c|c|}
\hline & \multicolumn{2}{|c|}{ Control } & \multicolumn{2}{|c|}{ Active } \\
\hline & Mean & SE & Mean & SE \\
\hline \multicolumn{5}{|l|}{ Systolic blood pressure (mmHg) } \\
\hline Fasting & 111 & 2 & 112 & 2 \\
\hline $2 \mathrm{~h}$ after dose consumption & 114 & 2 & $118^{*}$ & 2 \\
\hline \multicolumn{5}{|l|}{ Diastolic blood pressure (mmHg) } \\
\hline Fasting & 69 & 2 & 71 & 1 \\
\hline $2 \mathrm{~h}$ after dose consumption & 71 & 2 & 73 & 2 \\
\hline \multicolumn{5}{|l|}{ Heart rate (beats/min) } \\
\hline Fasting & 62 & 1 & 62 & 1 \\
\hline $2 \mathrm{~h}$ after dose consumption & 60 & 1 & $62^{*}$ & 1 \\
\hline
\end{tabular}

* Mean values were significantly different from those of the control treatment $(P=0.02)$.

†Data were obtained from the mixed model procedure in SAS. Tukey's post hoc comparison test was used for multiple comparisons. 
Table 6. Effects of treatments on the fasting markers of metabolic variables, inflammation and renin/angiotensin-converting enzyme (ACE) activitył

(Adjusted mean values with their standard errors)

\begin{tabular}{|c|c|c|c|c|c|c|}
\hline & \multicolumn{2}{|c|}{ Pre-treatment } & \multicolumn{2}{|c|}{ Control } & \multicolumn{2}{|c|}{ Active } \\
\hline & Mean & SE & Mean & SE & Mean & SE \\
\hline Total cholesterol (mg/l) & 1970 & 70 & 1950 & 80 & 1960 & 80 \\
\hline TAG (mg/l) & 1070 & 80 & 1060 & 110 & 1170 & 100 \\
\hline HDL-cholesterol (mg/l) & 530 & 30 & 530 & 30 & 540 & 30 \\
\hline LDL-cholesterol (mg/l) & 1230 & 60 & 1210 & 80 & 1180 & 70 \\
\hline IL-1 (pg/ml) & 0.09 & 0.02 & $0 \cdot 16$ & 0.03 & 0.11 & 0.02 \\
\hline IL-6 (pg/ml) & 1.24 & 0.19 & 0.99 & 0.23 & $1 \cdot 18$ & 0.22 \\
\hline TNF- $\alpha$ (pg/ml) & 0.99 & 0.12 & $1 \cdot 12$ & 0.14 & 1.03 & 0.14 \\
\hline Glucose (mg/l) & 902 & 17 & 919 & 23 & 929 & 23 \\
\hline Insulin $(\mu \mathrm{U} / \mathrm{ml})^{\star} \S$ & 8.6 & 0.8 & $11.8 \dagger$ & 1.1 & 9.5 & $1 \cdot 1$ \\
\hline HOMA-IR* & 1.9 & 0.20 & $2 \cdot 7 \dagger$ & 0.27 & $2 \cdot 23$ & 0.27 \\
\hline ACE activity (units/l) & $37 \cdot 7$ & 1.9 & $36 \cdot 5$ & $2 \cdot 2$ & $38 \cdot 2$ & $2 \cdot 1$ \\
\hline Renin (ng/ml per h) & 0.49 & 0.07 & 0.56 & 0.11 & 0.60 & 0.11 \\
\hline Angiotensin II (pg/ml) & $5 \cdot 2$ & 1.4 & 5.4 & $2 \cdot 2$ & $8 \cdot 0$ & $2 \cdot 1$ \\
\hline
\end{tabular}

HOMA-IR, homeostatic model assessment of insulin resistance.

*There was a significant main effect of treatment $(P=0.01)$.

$\dagger$ Mean values were significantly different from those of the pre-treatment $(P=0.009)$.

$\ddagger$ Data were obtained from the mixed model procedure in SAS. Tukey's post hoc comparison test was used for multiple comparisons.

$\S$ Insulin: $1 \mu \mathrm{U} / \mathrm{ml}$ is equivalent to $6.45 \mathrm{pmol} / \mathrm{l}$

acute responses are recorded at the end of a lengthy treatment period, are an effective strategy to tease out acute and chronic effects. Furthermore, we used a relatively high dose of cocoa products, including $37 \mathrm{~g}$ of dark chocolate and a beverage containing $11 \mathrm{~g}$ of natural cocoa. Several recent studies have suggested that smaller amounts of cocoa or dark chocolate can also enhance vasodilation $^{(12)}$. Monahan et al. ${ }^{(12)}$ measured the acute change in FMD after varying doses of cocoa, ranging from 2 to $26 \mathrm{~g}$. Significant increases in FMD ( $v$. the fasting baseline) were observed $2 \mathrm{~h}$ after the ingestion of 5,13 and $26 \mathrm{~g}$ of cocoa, with larger increases being observed after the consumption of higher doses. Although vascular effects of chocolate/cocoa are often attributed to their antioxidant compounds, we did not assess the measures of oxidative stress in the present study. This limits our ability to draw conclusions about the mechanism responsible for vasodilation.

In conclusion, in the present placebo-controlled, randomised trial, we observed substantial reductions in vascular constriction in the brachial artery in men and women after 4 weeks of daily consumption of cocoa and dark chocolate. The magnitude of blood flow during reactive hyperaemia, as measured by Doppler, also increased significantly with the cocoa + dark chocolate treatment. These changes may have been caused by the enhanced release of NO, although FMD of the brachial artery and RHI remained unchanged. We observed a substantial reduction in the AI in women, indicating greater compliance of conduit arteries or decreases in the constriction of peripheral arterioles. The cocoa + dark chocolate treatment produced no significant changes in fasting lipid, glucose, insulin or TAG levels. Although these data were obtained from only a subset of the study population, our findings are in agreement with those of studies showing little effect of chocolate on the lipid profile in individuals with normal cholesterol levels. Overall, the present study provides additional evidence that regular ingestion of natural cocoa and dark chocolate is beneficial for maintaining cardiovascular health, without adverse effects on body weight or body composition.

\section{Acknowledgements}

The General Clinical Research Center of The Pennsylvania State University is appreciated for providing its services. The present study was supported by National Institutes of Health Grant M01 RR 10732 and funded by The Hershey Company. D. L. M. and A. G. P. are employees of The Hershey Company. D. L. M. and A. G. P. contributed to the study design and manuscript development.

S. G. W., D. L. M., A. G. P. and A. C. S.-R. designed the research; M. D. M., M. J. P., N. P., P. W., L. F. G. and A. C. S.-R. conducted the research; A. C. S.-R. carried out the biochemical analyses; S. G. W. carried out the statistical analyses; S. G. W. prepared the manuscript; S. G. W. was responsible for its final content. All authors read and approved the final manuscript.

S. G. W. has received research funding and travel support from The Hershey Company. D. L. M. and A. G. P. are employees of The Hershey Company. None of the other authors has any personal or financial conflicts of interest.

\section{References}

1. Vanhoutte PM, Shimokawa H, Tang EH, et al. (2009) Endothelial dysfunction and vascular disease. Acta Physiol (Oxf) 196, 193-222.

2. Vita JA (2003) Tea consumption and cardiovascular disease: effects on endothelial function. J Nutr 133, 3293S-3297S.

3. Ras RT, Zock PL \& Draijer R (2011) Tea consumption enhances endothelial-dependent vasodilation; a meta-analysis. PLOS One 6, e16974. 
4. Coimbra SR, Lage SH, Brandizzi L, et al. (2005) The action of red wine and purple grape juice on vascular reactivity is independent of plasma lipids in hypercholesterolemic patients. Braz J Med Biol Res 38, 1339-1347.

5. Andrade AC, Cesena FH, Consolim-Colombo FM, et al. (2009) Short-term red wine consumption promotes differential effects on plasma levels of high-density lipoprotein cholesterol, sympathetic activity, and endothelial function in hypercholesterolemic, hypertensive, and healthy subjects. Clinics (Sao Paulo) 64, 435-442.

6. Fisher ND, Hughes M, Gerhard-Herman M, et al. (2003) Flavanol-rich cocoa induces nitric-oxide-dependent vasodilation in healthy humans. J Hypertens 21, 2281-2286.

7. Heiss C, Dejam A, Kleinbongard P, et al. (2003) Vascular effects of cocoa rich in flavan-3-ols. JAMA 290, 1030-1031.

8. Engler MB, Engler MM, Chen CY, et al. (2004) Flavonoid-rich dark chocolate improves endothelial function and increases plasma epicatechin concentrations in healthy adults. $J \mathrm{Am}$ Coll Nutr 23, 197-204.

9. Farouque HM, Leung M, Hope SA, et al. (2006) Acute and chronic effects of flavanol-rich cocoa on vascular function in subjects with coronary artery disease: a randomized double-blind placebo-controlled study. Clin Sci (Lond) 111, $71-80$.

10. Heiss C, Finis D, Kleinbongard P, et al. (2007) Sustained increase in flow-mediated dilation after daily intake of highflavanol cocoa drink over 1 week. J Cardiovasc Pharmacol Ther 49, 74-80.

11. Balzer J, Rassaf T, Heiss C, et al. (2008) Sustained benefits in vascular function through flavanol-containing cocoa in medicated diabetic patients: a double-masked, randomized, controlled trial. J Am Coll Cardiol 51, 2141-2149.

12. Monahan KD, Feehan RP, Kunselman AR, et al. (2011) Dosedependent increases in flow-mediated dilation following acute cocoa ingestion in healthy older adults. J Appl Physiol 111, 1568-1574.

13. Njike VY, Faridi Z, Shuval K, et al. (2011) Effects of sugarsweetened and sugar-free cocoa on endothelial function in overweight adults. Int J Cardiol 149, 83-88.

14. Shrime MG, Bauer SR, McDonald AC, et al. (2011) Flavonoidrich cocoa consumption affects multiple cardiovascular risk factors in a meta-analysis of short-term studies. J Nutr 141, 1982-1988.

15. Vlachopoulos C, Aznaouridis K, Alexopoulos N, et al. (2005) Effect of dark chocolate on arterial function in healthy individuals. Am J Hypertens 18, 785-791.

16. Schroeter H, Heiss C, Balzer J, et al. (2006) Epicatechin mediates beneficial effects of flavanol-rich cocoa on vascular function in humans. Proc Natl Acad Sci U S A 103, $1024-1029$.

17. Faridi Z, Njike VY, Dutta S, et al. (2008) Acute dark chocolate and cocoa ingestion and endothelial function: a randomized controlled crossover trial. Am J Clin Nutr 88, 58-63.

18. Davison K, Coates AM, Buckley JD, et al. (2008) Effect of cocoa flavanols and exercise on cardiometabolic risk factors in overweight and obese subjects. Int J Obes 32, 1289-1296.

19. Knorr M, Hausding M, Kroller-Schuhmacher S, et al. (2011) Nitroglycerin-induced endothelial dysfunction and tolerance involve adverse phosphorylation and $S$-glutathionylation of endothelial nitric oxide synthase: beneficial effects of therapy with the AT1 receptor blocker telmisartan. Arterioscler Thromb Vasc Biol 31, 2223-2231.

20. Vlachopoulos CV, Alexopoulos NA, Aznaouridis KA, et al. (2007) Relation of habitual cocoa consumption to aortic stiffness and wave reflections, and to central hemodynamics in healthy individuals. Am J Cardiol 99, 1473-1475.
21. Nichols WW \& Epstein BJ (2009) Actions of selected cardiovascular hormones on arterial stiffness and wave reflections. Curr Pharm Des 15, 304-320.

22. Payne M, Hurst W, Stuart D, et al. (2010) Determination of total procyanidins in selected chocolate and confectionery products using DMAC. J AOAC Int 93, 89-96.

23. Heffernan KS, Kuvin JT, Sarnak MJ, et al. (2011) Peripheral augmentation index and vascular inflammation in autosomal dominant polycystic kidney disease. Nephrol Dial Transplant 26, 2515-2521.

24. Patvardhan E, Heffernan KS, Ruan J, et al. (2011) Augmentation index derived from peripheral arterial tonometry correlates with cardiovascular risk factors. Cardiol Res Pract 2011, 253758.

25. Recio-Rodriguez JI, Gomez-Marcos MA, Patino-Alonso MC, et al. (2012) Cocoa intake and arterial stiffness in subjects with cardiovascular risk factors. Nutr J 11, 8.

26. Ou B, Hampsch-Woodill M \& Prior RL (2001) Development and validation of an improved oxygen radical absorbance capacity assay using fluorescein as the fluorescent probe. J Agric Food Chem 49, 4619-4626.

27. Huang D, Ou B, Hampsch-Woodill M, et al. (2002) Development and validation of oxygen radical absorbance capacity assay for lipophilic antioxidants using randomly methylated beta-cyclodextrin as the solubility enhancer. J Agric Food Chem 50, 1815-1821.

28. Singleton VL \& Rossi JA (1965) Colorimetry of total phenolics with phosphomolybdic-phosphotungstic acid reagents. Am J Enol Vitic 16, 144-158.

29. Nelson BC \& Sharpless KE (2003) Quantification of the predominant monomeric catechins in baking chocolate standard reference material by LC/APCI-MS. J Agric Food Chem 51, 531-537.

30. Hurst W, Stanley B, Glinski J, et al. (2009) Characterization of primary standards for use in the HPLC analysis of the procyanidin content of cocoa and chocolate containing products. Molecules 14, 4136-4146.

31. Robbins RJ, Leonczak J, Johnson JC, et al. (2009) Method performance and multi-laboratory assessment of a normal phase high pressure liquid chromatography-fluorescence detection method for the quantitation of flavanols and procyanidins in cocoa and chocolate containing samples. J Chroma A 1216, 4831-4840.

32. Centers for Disease Control and Prevention (CDC), National Center for Health Statistics (NCHS), National Health and Nutrition Examination Survey Data \& Hyattsville MUSDoH (1994) Plan and operation of the Third National Health and Nutrition Examination Survey, 1988-94. Series 1: programs and collection procedures. Vital Health Stat 1, 1-407.

33. Baba S, Osakabe N, Yasuda A, et al. (2000) Bioavailability of (-)-epicatechin upon intake of chocolate and cocoa in human volunteers. Free Radic Res 33, 635-641.

34. Celermajer DS, Sorensen KE, Gooch VM, et al. (1992) Noninvasive detection of endothelial dysfunction in children and adults at risk of atherosclerosis. Lancet 340, 1111-1115.

35. West SG, Wagner P, Schoemer SL, et al. (2004) Biological correlates of day-to-day variation in flow-mediated dilation in individuals with type 2 diabetes: a study of test-retest reliability. Diabetologia 47, 1625-1631.

36. West SG, Hecker KD, Mustad VA, et al. (2005) Acute effects of monounsaturated fatty acids with and without omega-3 fatty acids on vascular reactivity in individuals with type 2 diabetes. Diabetologia 48, 113-122.

37. Bonetti PO, Pumper GM, Higano ST, et al. (2004) Noninvasive identification of patients with early coronary 
atherosclerosis by assessment of digital reactive hyperemia. $J$ Am Coll Cardiol 44, 2137-2141.

38. McCrea CE, Skulas-Ray AC, Chow M, et al. (2012) Test-retest reliability of pulse amplitude tonometry measures of vascular endothelial function: implications for clinical trial design. Vasc Med 17, 29-36.

39. Rubinshtein R, Kuvin JT, Soffler M, et al. (2010) Assessment of endothelial function by non-invasive peripheral arterial tonometry predicts late cardiovascular adverse events. Eur Heart J 31, 1142-1148.

40. Hamburg N, Keyes M \& Larson M (2008) Cross-sectional relations of digital vascular function to cardiovascular risk factors in the Framingham Heart Study. Circulation 117, $2467-2474$.

41. Hamburg NM \& Benjamin EJ (2009) Assessment of endothelial function using digital pulse amplitude tonometry. Trends Cardiovasc Med 19, 6-11.

42. Wilkinson IB, MacCallum H, Flint L, et al. (2000) The influence of heart rate on augmentation index and central arterial pressure in humans. J Physiol 525, 263-270.

43. Persson IA, Persson K, Hagg S, et al. (2011) Effects of cocoa extract and dark chocolate on angiotensin-converting enzyme and nitric oxide in human endothelial cells and healthy volunteers - a nutrigenomics perspective. J Cardiovasc Pharmacol 57, 44-50.

44. Morgan C \& Lazarow A (1963) Immunoassay of insulin: two antibody system. Plasma insulin levels in normal, subdiabetic, and diabetic rats. Diabetes 12, 115-126.

45. Bonora E, Formentini G, Calcaterra F, et al. (2002) HOMAestimated insulin resistance is an independent predictor of cardiovascular disease in type 2 diabetic subjects: prospective data from the Verona Diabetes Complications Study. Diabetes Care 25, 1135-1141.

46. Hooper L, Kroon PA, Rimm EB, et al. (2008) Flavonoids, flavonoid rich foods, and cardiovascular risk: a meta analysis of randomized trials. Am J Clin Nutr 88, 38-50.

47. Karim M, McCormick K \& Kappagoda CT (2000) Effects of cocoa extracts on endothelium-dependent relaxation. $J$ Nutr 130, 2105S-2108S.

48. Schnorr O, Brossette T, Momma TY, et al. (2008) Cocoa flavanols lower vascular arginase activity in human endothelial cells in vitro and in erythrocytes in vivo. Arch Biochem Biophys 476, 211-215.
49. Ottaviani JI, Momma TY, Heiss C, et al. (2011) The stereochemical configuration of flavanols influences the level and metabolism of flavanols in humans and their biological activity in vivo. Free Radic Biol Med 50, 237-244.

50. Loke WM, Hodgson JM, Proudfoot JM, et al. (2008) Pure dietary flavonoids quercetin and (-)-epicatechin augment nitric oxide products and reduce endothelin-1 acutely in healthy men. Am J Clin Nutr 88, 1018-1025.

51. Heiss C, Kleinbongard P, Dejam A, et al. (2005) Acute consumption of flavanol-rich cocoa and the reversal of endothelial dysfunction in smokers. $\mathrm{J}$ Am Coll Cardiol 46, $1276-1283$.

52. Fisher ND \& Hollenberg NK (2006) Aging and vascular responses to flavanol-rich cocoa. J Hypertens 24, 1575-1580.

53. Crews WD Jr, Harrison DW \& Wright JW (2008) A doubleblind, placebo-controlled, randomized trial of the effects of dark chocolate and cocoa on variables associated with neuropsychological functioning and cardiovascular health: clinical findings from a sample of healthy, cognitively intact older adults. Am J Clin Nutr 87, 872-880.

54. Ried K, Sullivan T, Fakler P, et al. (2010) Does chocolate reduce blood pressure? A meta-analysis. BMC Med $\mathbf{8}, 39$.

55. Grassi D, Necozione S, Lippi C, et al. (2005) Cocoa reduces blood pressure and insulin resistance and improves endothelium-dependent vasodilation in hypertensives. Hypertension 46, 398-405.

56. Grassi D, Desideri G, Necozione S, et al. (2008) Blood pressure is reduced and insulin sensitivity increased in glucoseintolerant, hypertensive subjects after 15 days of consuming high-polyphenol dark chocolate. J Nutr 138, 1671-1676.

57. Berry NM, Davison K, Coates AM, et al. (2010) Impact of cocoa flavanol consumption on blood pressure responsivenes to exercise. Br J Nutr 103, 1480-1484.

58. Gosmanov AR, Smiley DD, Robalino G, et al. (2010) Effects of oral and intravenous fat load on blood pressure, endothelial function, sympathetic activity, and oxidative stress in obese healthy subjects. Am J Phys Endocrinol Metab 299, E953-E958.

59. Hooper L, Kay C, Abdelhamid A, et al. (2012) Effects of chocolate, cocoa, and flavan-3-ols on cardiovascular health: a systematic review and meta-analysis of randomized trials. Am J Clin Nutr 95, 740-751. 